
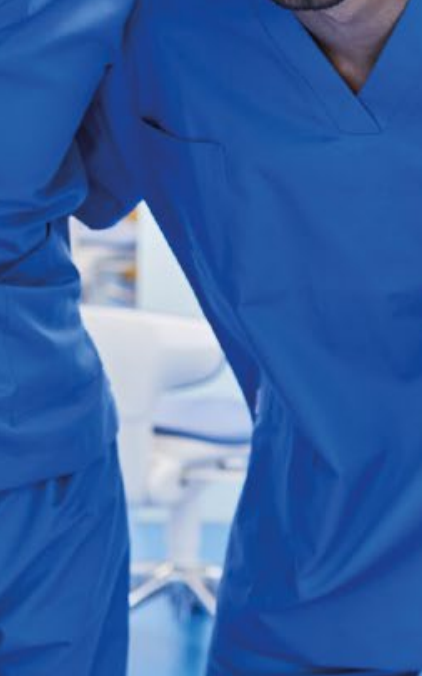

\title{
Tackling a challenging future head on
}

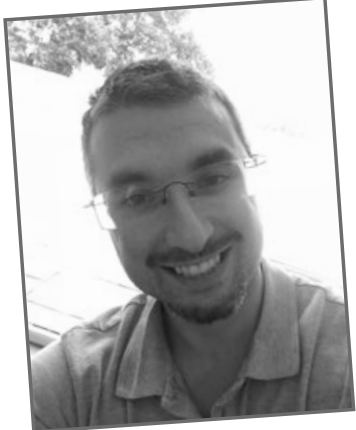

Ashkan Pitchforth founded South Cliff Dental Group in April 2015 following his desire to create a group of practices which puts patients' interests at its heart. Responsible for the overall strategy of the Group and its focus, I caught up with the CEO to talk NHS, private, aims, goals and the future.

How do you ensure a commitment to quality under the NHS contract?

AP South Cliff Dental Group (SCDG) has a clinical governance system in order to ensure consistently high levels of clinical competency and quality. SCDG employs a Head of Clinical Governance, Operations Manager and a team of Clinical Directors, forming our Clinical Governance Team (CGT).

The CGT works closely with all services to ensure that quality and continuous improvement is built into day-to-day activity, and that services continue to meet professional standards. In order to ensure clinical staff have the correct level of competencies, the CGT carries out clinical audits which are developed in an annual audit programme, and they ensure all teams take part in these audits. These audits are reviewed to facilitate the implementation of any changes as a result of any issues identified. Analysis of patient experiences through reviewing complaints, compliments and feedback from the Friends and Family Test (FFT), compared to our PREMs/PROMs, allows identification of shortcomings as well. The CGT uses this information to provide training to all staff.

At the local practice level, each practice has a practice manager, with them being the CQC Registered Manager and Caldicott Guardian, providing leadership to their staff members and the implementation of policies. The practice manager is accountable to the CGT and reports directly to them.
Clinical leadership to all NHS performers is currently provided by the Clinical Directors with all performers reporting concerns to their allocated Clinical Director. The Clinical Directors are able to provide direct clinical supervision to the performers.

All the clinical leads (Clinical Directors and Practice Managers) undertake Case Based Discussions (CBDs) and Direct Observation Procedures (DOPs) for their team to reassure NHE England key processes are undertaken in a safe manner, and quality is maintained under our contractual obligations.

\section{How do you as CEO see that this is being delivered?}

AP As the CEO, I am ultimately responsible for ensuring quality is being delivered and achieved, and thus regularly receive feedback from the Clinical Governance Team. Being a Dental Advisor for NHS England South East Region, I have received extensive training and guidance from both the Contracts and Performance Teams into the highest levels of standards which practices should aim to achieve, and every day we strive to ensure this level of quality is embedded into our practices. 
Are more and more patients willingly turning to private care, or is this influenced by the market?

AP Our practices have always been firm promoters of the NHS brand although in all our practices, as per the GDC Standards, we offer all patients both NHS and private treatment options. We are finding that a lot of patients visit the practices for an NHS examination, but tend to opt for more private treatment options such as hygienist visits, restorations for cosmetic purposes, and teeth whitening. We feel this is what gives us a competitive edge over fully private practices and ensure all our associate dentists have full appointment books.

\section{As CEO how hands on do you like to be?}

AP Very hands-on. I often visit the practices; meet with associates and managers; and constantly review the performance of the practices. My working day (which is in excess of 12 hours a day) is focused heavily towards the performance and effectiveness of the practices.

\section{How do you judge the success of the} Group and its aims?

AP Success is judged against key themes and goals which are set each year and the group as a whole work towards achieving this. These goals are broken down into monthly targets which are monitored throughout the year. Practices compete with each other through our yearly competitions which can result in employees winning iPads, Apple Watches and cash prizes. We are heavily focused on patient reviews and feedback.

\section{Have you been affected by the} recruitment crisis? If so, how have you attempted to remedy this, and if not why do you think it is?

AP I believe we have managed to fully engage our practices with performers - our performer retention rate is $90 \%$ each year. If we need to recruit, we utilise recruitment agencies and can advertise via the BDJJobs and other online platforms. Our team of four Clinical Directors are all NHS performers and thus able to work clinically should the need arise. We have a rolling PVLE training process where a number of PVLE dentists are being mentored at any one point. These dentists have committed themselves to two years of service within our organisation, and we receive a vast number of referrals from their colleagues looking to undertake PVLE training within our practices.
SCDG holds a Tier 2 sponsorship licence so we are unique in being able to offer work visas to oversee dentists. At a number of our practices we undertake Foundation Training which aids in bringing in 'fresh blood' yearon-year into our group.

You offer late evening and weekend appointments - to what extent does that help to cut down on DNAs and help your patient base?

AP This assists immensely. These are the most popular times for patients to attend to see the dentist and thus our Failure to Attend rate in evenings and weekends is less than one per cent a month. Additionally, our patient base has grown immensely by offering these appointment slots.

\section{Sustainability is mentioned on the} website. How important is that to you? AP Sustainability is extremely important to us. It's our aim to utilise the core values of the Public Services (Social Value) Act 2012 to shape the improvement our company makes in the local area. We undertake the training of trainee dental nurses, through our partners Acacia Training. Local residents are employed as staff, which creates jobs within the community. As part of the UK's Plan for Growth Agenda, our intention is to create an educated workforce which we implement through our in-house CPD courses. In 2019 we linked with the University of Portsmouth Dental Academy to put on a Composite course specifically for our associate dentists. We pride ourselves on the use of digital technology such as paperless patient records; and the use of our unique Staff Online Portal (SOP) for accessing of documents and task setting. This reduces the environmental impact of waste paper. Labour standards are monitored through annual appraisals and pay reviews in line with the NHS Terms and Conditions (AfC) pay scales.

In combination with NHS England's FYFV for Mental Health, we encourage wellbeing amongst our staff members with a dedicated Staff Welfare Officer. SCDG collaborates with the community sector, by working with Schools, Nurseries and Care Homes to improve access provision. We have increased recycling of materials by over $53 \%$ over the last three years and reduced our carbon footprint through simple methods such as staff car-sharing to travel to work. In our Westbury practice, we exclusively use Renewable Green energy from Engie UK.
Stress is rife in the profession - how do you manage the workload of multiple practices across multiple locations, and how do you help to support staff so they don't feel the pinch?

AP My ethos to work:life is that 'nobody has ever drowned in their own sweat'. On weekdays, my alarm goes off at 5.30am, and by $6 \mathrm{am} \mathrm{I} \mathrm{am} \mathrm{in} \mathrm{the} \mathrm{gym.} \mathrm{Working} \mathrm{out} \mathrm{at} \mathrm{the}$ beginning of each day for one hour relieves all my stress and enables me to start the day feeling fresh and with a clear mind. I arrive in the office by 7.30am and work through until approximately $9 \mathrm{pm}$. On arrival home, I have dinner with my wife and catch up on the day. I complete work emails from 10pm until usually midnight/1am whilst watching a new film every evening. My weekends are spent totally free of work when I devote this time to my 8-year old daughter and 7-month old son.

For staff, we promote regular breaks and help all employees to feel supported, offering guidance where required. We work hard, but play hard too. We encourage regular (weekly) practice events, such as night outs or simply finishing off the week in a local bar. Our Christmas Party 2019 was an extravaganza in the Park Plaza in London, Riverbank. Our Instagram page shows a prolifera of social events we have undertaken recently.

\section{What challenges do you foresee you overcoming in the future, and how does your ethos stand you in good stead to overcome those?}

AP The challenges in the future is the uncertainty of the NHS prototype contract but with our dedication to NHS England, we feel that if we put the interest of patients first, then we can work with the commissioner to overcome any new contract which could potentially be challenging. I personally feel the Contract Managers and Officers at NHS England are a credit to our organisation, as well as their advisors. A vast majority of practices or groups might not want to engage well with them, but we feel engagement with them is crucial to keep developing an NHS brand that we can all be proud of.

https://doi.org/10.1038/s41404-020-0306-y

Ashkan qualified from Guy's, King's and St Thomas' Dental School in 2009 with honours. He is an Executive Member of the West Sussex Local Dental Committee, and additionally works as a Clinical Dental Advisor for NHS England South East Region 